\title{
AS EXPERIÊNCIAS DA PUBLICIZAÇÃO NO ESTADO DA BAHIA - A PARCERIA DA ADMINISTRAÇÃO PÚBLICA COM ORGANIZAÇÕES SOCIAIS
}

\author{
Efson Batista Lima*
}

\begin{abstract}
RESUMO: O Estado brasileiro diante do seu objetivo de criar estruturas e prestar serviços de interesse público acolheu em seu ordenamento jurídico mecanismos que possibilitam à prestação de serviços públicos com eficiência e menor custo mediante o escopo da descentralização. Um desses institutos é a parceria entre a Administração Pública e o Terceiro Setor. Em razão disto, a investigação analisa, especialmente, os casos da publicização envolvendo as áreas da saúde e do trabalho no Estado da Bahia. A pesquisa foi conduzida com base em referencial bibliográfico, em relatórios técnicos, no marco legal e na decisão do STF em face da ADI - 1923.
\end{abstract}

Palavras-chave: Administração Pública; Publicização; Terceiro Setor; Organizações Sociais.

\section{THE EXPERIENCES OF PUBLICIZATION IN THE STATE OF BAHIA - THE PARTNERSHIP OF PUBLIC ADMINISTRATION WITH SOCIAL ORGANIZATIONS}

\begin{abstract}
The brazilian State, faced with its objective of creating structures and providing services of public interest, has incorporated in its legal system mechanisms that allow the provision of public services with efficiency and lower costs through the scope of decentralization. One of these institutes is the partnership between the Public Administration and the Third Sector. Because of this, the investigation examines, in particular, the cases of publicity involving the areas of health and work in the State of Bahia. The research was conducted based on bibliographic references, technical reports, legal frameworks and the STF decision in the face of ADI - 1923.
\end{abstract}

Keywords: Public administration; Publication; Third sector; Social Organizations; Brazil.

\footnotetext{
* Doutorando em Direito/UFBA. Mestre em Direito/UFBA. Especialista Gestão em Saúde/FIOCRUZ. Professor da Faculdade 2 de Julho. Coordenador da Pós-graduação, Pesquisa e Extensão da Faculdade 2 de Julho.
}

Rev. de Direito Administrativo E Gestão Pública | e-ISSN: 2526-0073 | Porto Alegre | v. 4 | n. 2 | p. 137 - 151 | Jul/Dez. 2018 


\section{INTRODUÇÃO}

A Constituição Federal de 1988 estabeleceu diversos direitos para os cidadãos e visando sua garantia, o Estado brasileiro atua em duas grandes vertentes: em uma frente fiscaliza o cumprimento da lei, limitando condutas e punindo infratores e, em outra, cria estruturas e presta serviços de interesse público.

Em relação à prestação dos serviços públicos, o Estado não foi (tem sido) poupado das críticas em relação à qualidade e a demora na prestação dos seus serviços. Sendo assim, a administração pública objetivando melhorar a prestação dos serviços por diversas vezes tem recorrido às organizações do terceiro setor.

Não é novidade afirmar que a participação de entidades do terceiro setor na prestação de serviços à população brasileira pode ser verificada nos primeiros anos do Brasil colônia e se mantém até a quadra atual, especialmente, na área de saúde.

Sendo assim, não foi difícil prevê no ordenamento jurídico pátrio a atuação dessas organizações, que ora são elogiadas, ora são criticadas. De todo modo, em apertada síntese, atualmente, existem no Brasil, as seguintes modalidades de parceria entre a administração pública e o terceiro setor: contratos de gestão - celebrados com entidades qualificadas como Organizações Sociais (OS); termos de parceria - celebrados com entidades qualificadas como Organizações da Sociedade Civil de Interesse Público (OSCIP); termos de colaboração, termos de fomento e acordos de cooperação - celebrados com organizações da sociedade civil. Sendo estes últimos, inovações advindas da Lei n. ${ }^{\circ}$ 13.019/14.

Diante da existência desses arranjos no Brasil e mediante o pioneirismo do Estado da Bahia no que diz respeito à celebração de contratos de gestão em território nacional, torna-se significativa fazer uma análise comparada, buscando verificar a origem dos contratos de gestão, especialmente, em relação aos modelos inglês e francês, responsáveis por influenciar o modelo pátrio.

Por outro lado, visando oferecer uma relação prática ao trabalho, a pesquisa adotará como pano de fundo às parcerias celebradas entre a administração pública e o terceiro setor no tocante à publicização de serviços no Estado da Bahia após a reforma implementada do Estado brasileiro na década de noventa do Século XX.

Para isto, a investigação busca verificar o antecedente histórico do instituto do contrato

Rev. de Direito Administrativo E Gestão Pública | e-ISSN: 2526-0073 | Porto Alegre | v. 4 | n. 2 | p. 137 -151 | Jul/Dez. 2018 
de gestão apresentando suas perspectivas históricas e é conduzida com base em referencial bibliográfico.

\section{O PIONEIRISMO DA BAHIA EM RELAÇÃO AOS CONTRATOS DE GESTÃO}

O Estado da Bahia, antecipando a inserção no ordenamento jurídico brasileiro dos contratos de gestão, cuja ação foi parte das diretrizes da reforma do estado brasileiro nos anos noventa do século XX, tornou-se um dos pioneiros na implantação do Programa Estadual de Publicização de Serviços Públicos para Organizações Sociais. ${ }^{1}$

Desse modo, buscou a implementação de um marco legal que viabilizasse a transferência de serviços públicos para entidades de direito privado sem fins lucrativos.

O Estado da Bahia instituiu, em 1997, o seu modelo de publicização, sendo a área da saúde a primeira a implantar e, posteriormente, as áreas de educação, agricultura, cultura e, após 15 anos, a área do trabalho, precisamente, no ano de 2012, com o objetivo de prestar e gerenciar o serviço de assistência técnica aos empreendimentos associativos populares e as a redes de economia solidária.

Enquanto na saúde as organizações sociais selecionadas foram atuar, predominantemente, dentro das estruturas hospitalares já existentes; na área do trabalho a implantação das instalações físicas e o gerenciamento do serviço estiveram sob responsabilidade das entidades do terceiro setor que foram selecionadas para prestação do serviço na área do trabalho.

A busca pela eficiência na prestação do serviço público e a agilidade para que o Estado cumprisse exitosamente as suas funções exclusivas formaram o discurso de que era necessária a reconstrução do Estado "para que este pudesse realizar não apenas suas tarefas clássicas de garantia da propriedade e dos contratos, mas também seu papel de garantidor dos direitos sociais e de promotor da competitividade". ${ }^{2}$

Além da eficiência esperada em relação à prestação do serviço, existem as implicações com a Lei de Responsabilidade Fiscal no tocante aos limites de gastos com pessoal e as

\footnotetext{
${ }^{1}$ COELHO FILHO, Milton de Sousa. 15 ANOS DE ORGANIZAÇÕES SOCIAIS: o modelo baiano. $5^{\circ}$ Congresso de Gestão Pública. Brasília, 2012. Disponível em: http://www.organizacoessociais.com.br/wpcontent/uploads/2015/12/15_anos_de_organiza\%C3\%A7\%C3\%B5es_sociais_o_modelo_baiano.pdf. Acesso em: 06 jul. 2018.

2 BRESSER PEREIRA, Luis Carlos. A reforma do Estado dos Anos 90: lógica e mecanismos de controle. Lua Nova. n. 45,98 , p. 7
}

Rev. de Direito Administrativo E Gestão Pública | e-ISSN: 2526-0073 | Porto Alegre | v. 4 | n. 2 | p. 137 - 151 | Jul/Dez. 2018 
imposições quanto à seleção de pessoal, circunstâncias que favorecem a publicização dos serviços públicos.

A adoção do modelo de gestão por organizações sociais sustenta-se no pressuposto de que, por essa via, em comparação com a gestão direta dos serviços pelo Estado, haveria maior flexibilidade administrativa e autonomia, foco no cidadão, controle social e compromisso com os resultados (metas).

Sendo assim, a publicização dos serviços públicos não exclusivos tem permitido a consolidação do terceiro setor como um campo específico do direito e importante mecanismo para o Estado executar direitos fundamentais sob a égide da eficiência administrativa e da economicidade, permitindo-o a cumprir e se concentrar em suas funções clássicas, além de buscar melhorar a governança pública.

\subsection{As Motivações para a Publicização das Áreas Saúde e Trabalho na Bahia}

A prestação do serviço na área da saúde de forma eficiente é fundamental para a afirmação da cidadania e não obstante é uma das prestações de serviços mais sensíveis à opinião pública. Outro aspecto importante é que o tema esteve diretamente relacionado com a reorganização dos Estados nacionais na década de noventa, especialmente, o brasileiro, que viu na publicização uma forma de transferir os serviços públicos para entidades do terceiro setor, que privadas, mas com objetivos de atender os cidadãos.

Encontra-se também o argumento econômico - porque apresenta uma economia para o estado quando comparada a prestação dos serviços públicos transferidos e os prestados diretamente.

Soma-se ainda a tendência de conjugação de esforços e recursos entre as entidades estatais e a iniciativa privada, buscando ampliar a eficácia na utilização dos recursos econômicos, os quais não estão sempre disponíveis e gerar serviços públicos eficientes e dotados de qualidade e menor custo. ${ }^{3}$

No Estado da Bahia há mais de cem entidades qualificadas como organizações sociais. O número de contratos de gestão estabelecidos entre o Estado da Bahia e as entidades qualificadas como organizações sociais foi ampliado em quase $60 \%$ nos últimos cinco anos. Este crescimento propiciou a oferta de serviços à população baiana nas áreas de saúde, ensino,

\footnotetext{
${ }^{3}$ JUSTEN FILHO, Marçal. Curso de Direito Administrativo. $2^{\text {a }}$ ed. rev. e atual. São Paulo: Saraiva. 2006, p. 508.
} 
trabalho, ação social e agropecuária, com repasse anual de recursos públicos da ordem de $\mathrm{R} \$$ 588,6 milhões em 2015. ${ }^{4}$ Atualmente, 1/3 dos leitos da área saúde financiados pelo Estado da Bahia estão sob responsabilidade direta de organizações sociais.

Então, verifica-se um movimento iniciado nos finais da década de oitenta e anos noventa em que o Estado caminha em direção ao terceiro setor, cujo movimento em direção ao setor público não-estatal, no sentido de transferir a execução de serviços que não envolvem o exercício de poder do Estado, mas que devem ser subsidiados pelo Estado, como é o caso dos serviços de educação, saúde, cultura e pesquisa científica, tem sido chamado de publicização.

A publicização acontece por meio de um programa, cujo objetivo é transferir para o setor público não estatal, o denominado terceiro setor, a produção dos serviços competitivos ou não-exclusivos do Estado, estabelecendo-se um sistema de parceria entre Estado e sociedade civil organizada.

Desse modo, o Estado abandona o papel de executor ou prestador direto de serviços, mantendo-se, entretanto, no papel de regulador e provedor ou promotor destes, principalmente dos serviços sociais, como educação e saúde, que são essenciais para o desenvolvimento, na medida em que envolvem investimento em capital humano. Como promotor desses serviços o Estado continuará a subsidiá-los, buscando, ao mesmo tempo, o controle social direto e a participação da sociedade. ${ }^{5}$

Não obstante, a deficiência do setor público na prestação de serviços públicos permite que o terceiro setor assuma um papel de fundamental importância para a sociedade, a exemplo da defesa dos direitos da mulher, dos indígenas do consumidor, das crianças e do meio ambiente entre outros direitos. Assim, a expansão do terceiro setor possui caráter estratégico e de significativa relevância para qualquer sociedade que se preocupa com o desenvolvimento social e consolidação de seus valores democráticos comprometidos com a solidariedade humana. A melhoria da qualidade de vida das pessoas é o objetivo central da sociedade civil organizada.

\footnotetext{
4 AVANÇO DO PROGRAMA ESTADUAL DE ORGANIZAÇÕES SOCIAIS AMPLIA SERVIÇOS PRESTADOS À POPULAÇÃO BAIANA. Disponível http://www.saeb.ba.gov.br/NoticiasView.aspx?noticia=7622-avanco-do-programa-estadual-de-organizacoessociais-amplia-servicos-prestados-a-populacao-baiana. Acesso em: 06 jul. 2016.

${ }^{5}$ BRASIL. Ministério da Administração Federal e Reforma do Estado. Organizações Sociais. Brasília: 1997, p.9.
} 


\section{OS FUNDAMENTOS DA PUBLICIZAÇÃO NA FRANÇA, NA INGLATERRA E NO} BRASIL

As mudanças que aconteceram no ambiente político, social e econômico, a pressão da sociedade por serviços de melhor qualidade e a necessidade do Estado de concentrar seus esforços naquelas atividades que não podem ser exercidas por outro ente, direcionaram a administração pública buscar, no mundo, especialmente, modelos modernos e eficientes de gestão organizacional, que fortaleçam parcerias com o setor privado e lhe transfira responsabilidade na execução de serviços.

As reformas estatais implementadas no Brasil na década de noventa não foi somente um fenômeno nacional, podemos encontrar os relatos na obra La Transformación del Estad, de Palazzo, Sésin e Lembeye (1992).

É uma constante nas relações da contemporaneidade que está relacionada com a conjugação de esforços e recursos entre as entidades estatais e o setor privado, visando à eficácia na utilização dos recursos econômicos e geração de serviços públicos mais eficientes racionalizados a partir da qualidade e do menor custo. ${ }^{6}$

Desse modo, a publicização do serviço público é um dos modelos encontrados para a implementação de políticas públicas, que se constitui em meio para a realização de diretos fundamentais.

As organizações sociais são apontadas como de inspiração do direito inglês e que também é utilizado por diversos outros países, como aponta Di Pietro.

O modelo das organizações sociais foi inspirado nas quase autonomous governamental organizations - quangos do direito inglês e também utilizado por diversos outros países, como Austrália e a Nova Zelândia. Talvez, essa inspiração no direito inglês (que se insere no sistema do Common Law) justifique a dificuldade de enquadramento das organizações sociais nas categorias de pessoas jurídicas existentes no âmbito do direito administrativo brasileiro (que se insere no sistema de base romanística). ${ }^{7}$ (grifos da autora).

Cumpre asseverar que não há uma unanimidade em relação qual escopo o Brasil adotou, entretanto, a origem está associada aos modelos francês e inglês.

\footnotetext{
${ }^{6}$ JUSTEN FILHO, Marçal. Curso de Direito Administrativo. $2^{\mathrm{a}}$ ed. rev. e atual. São Paulo: Saraiva. 2006 , p. 508.

${ }^{7}$ DI PIETRO, Maria Sylvia Zanella. Direito Administrativo. 29. ed. São Paulo: Forense, 2016, p.618.
} 


\subsection{França}

A França, em busca de maior eficiência administrativa, empreendeu ampla reforma do aparelho estatal. Nesse país, o processo teve início com o Relatório Nora, publicado em abril de 1967, consoante narra Gustavo Justino de Oliveira, cujo documento possuía, basicamente, quatro recomendações:

(1) reconhecimento às empresas públicas de uma verdadeira autonomia de gestão; (2) incentivo à avaliação e à compensação das obrigações de serviço público impostas às empresas públicas; (3) melhoria da situação financeira das empresas públicas e (4) contratualização das relações entre o Estado e as empresas públicas. ${ }^{8}$

A partir dessas recomendações, iniciou-se na França o processo de contratualização da administração pública. Processo que incidiu, num primeiro momento, sobre as empresas públicas e seu controle por parte do Estado. Contratos de programa, de empresa, de plano e de objetivos se sucederam ao longo dos anos como instrumento principal da reforma da administração pública francesa.

E a partir de 1995, com a Circular Juppé, generalizou-se o modelo de gestão dos centros de responsabilidade. Modelo que se estendeu a outros órgãos, mediante os contratos de serviço e os contratos de estabelecimento público.

Então, percebe-se, então, que na França, na segunda metade da década de 60 surgiram dois modelos de gestão: contrato de plano e contrato de serviços, este aplicado a órgãos da administração direta, aquele às empresas públicas. Entretanto, nem sempre sua implementação foi uniforme passando ao longo do processo por mudanças.

\subsection{Inglaterra}

A Inglaterra, por sua vez, iniciou em 1979 uma nova experiência de gestão, pois os ingleses estavam em busca de uma transformação que fosse mais durável nas formas de gestão da Administração Pública. Para isso, era necessário reformar as estruturas dos sistemas de informação, gestão financeira e recursos humanos. Todo esse processo de reforma do Estado, na Inglaterra, se iniciou com a nomeação de Lord Rayner para o posto de Conselheiro da Primeira-Ministra Margareth Tatcher.

\footnotetext{
${ }^{8}$ OLIVEIRA, Gustavo Justino de. Contrato de gestão. São Paulo: Revista dos Tribunais, 2008. p. 77.
} 
A partir de então, foi concebida a Unidade de Eficiência (Efficiency Unity), que, antes de mais nada, era “[...] de uma pequena estrutura (dez pessoas), vinculada à Primeira- Ministra, [que] deveria catalisar o deslanche das avaliações nos ministérios, assegurar que essas avaliações fossem seguidas de ações e garantir a síntese e a difusão de ensinamentos de interesse geral $[\ldots] ., 9$

Conforme relata o estudo da Escola Nacional de Administração Pública.

\begin{abstract}
Uma das principais hipóteses da estratégia Rayner era que o processo de reforma deveria ser, em grande parte, interno, e que era necessário implementar ações específicas para promover a mobilização dos funcionários em favor das reformas. Essa hipótese explica a estrutura adotada para The Efficient Unity (EU) e seu método de trabalho. ${ }^{10}$
\end{abstract}

Como se percebe, tanto na França quanto na Inglaterra, buscou-se reformar o aparelho do Estado para atingir maior eficiência administrativa. Isso mediante instrumentos consensuais que, por um lado, deram maior autonomia aos agentes públicos e, por outro, deles cobraram mais responsabilidade.

O controle de resultados passou, então, a prevalecer sobre outros controles administrativos ou orçamentários.

\title{
3.3 Brasil
}

Como se vê, tanto na França quanto na Inglaterra, buscou-se reformar o aparelho do Estado para atingir maior eficiência administrativa. Isso mediante instrumentos consensuais que, por um lado, deram maior autonomia aos agentes públicos e, por outro, deles cobraram mais responsabilidade. O controle de resultados passou, então, a prevalecer sobre outros controles administrativos ou orçamentários.

Para Bresser Pereira, entre as atividades exclusivas de Estado e a produção de bens e serviços para o mercado, tem-se hoje, dentro do Estado, uma série de atividades na área social e científica que não lhe são exclusivas, que não envolvem poder de Estado. Para este autor, estão inclusas nesta categoria as escolas, as universidades, os centros de pesquisa científica e tecnológica, as creches, os ambulatórios, os hospitais, as entidades de assistência aos carentes,

\footnotetext{
${ }^{9}$ FUNDAÇÃO ESCOLA NACIONAL DE ADMINISTRAÇÃO PÚBLICA. O contrato de gestão no serviço público. Brasília: ENAP, 1993, p. 28.

${ }^{10}$ FUNDAÇÃO ESCOLA NACIONAL DE ADMINISTRAÇÃO PÚBLICA. O contrato de gestão no serviço público. Brasília: ENAP, 1993, p. 28.
}

Rev. de Direito Administrativo E Gestão Pública | e-ISSN: 2526-0073 | Porto Alegre | v. 4 | n. 2 | p. 137 - 151 | Jul/Dez. 2018 


\section{AS EXPERIÊNCIAS DA PUBLICIZAÇÃO NO ESTADO DA BAHIA - A PARCERIA DA \\ ADMINISTRAÇÃO PÚBLICA COM ORGANIZAÇÕES SOCIAIS}

os museus, as orquestras sinfônicas, as oficinas de arte, as emissoras de rádio e televisão educativa ou cultural.

De forma categórica, Bresser Pereira defende que estas são atividades competitivas e que podem ser controladas não apenas através da administração pública gerencial, mas também e, principalmente, através do controle social.

No caso em comento da publicização, o Estado passa de executor ou prestador direto de serviços para regulador, provedor ou promotor destes, principalmente dos serviços de interesse público atinentes ao ensino, à pesquisa científica, ao desenvolvimento tecnológico e institucional, à proteção e preservação do meio ambiente, bem como à saúde, ao trabalho, à ação social, à cultura, ao desporto e à agropecuária, essenciais para o desenvolvimento, na medida em que envolvem investimento em capital humano. Como provedor desses serviços, o Estado continuará a subsidiá-los, buscando, ao mesmo tempo, o controle social direto e a participação da sociedade.

Para o fenômeno da publicização, apontam determinadas vantagens para a administração pública e para a sociedade em geral, entre elas estão: a melhoraria da eficiência e da qualidade dos serviços prestados ao cidadão; redução das formalidades burocráticas para acesso aos serviços; dotar o agente executor de maior autonomia administrativa e financeira, contribuindo para agilizar e flexibilizar o gerenciamento da instituição; utilização dos recursos de forma mais racional, visando à redução de custos; priorizar a avaliação por resultados; e a promoção da maior integração entre os setores público, privado e a sociedade.

Para Modesto, as organizações sociais representam uma nova perspectiva, entretanto, adverte para que as mesmas não sejam superdimensionadas e tampouco terem seus papeis reduzidos nessa ótica que se descortina.

\footnotetext{
As organizações sociais representam uma nova estratégia de estimular parcerias de entidades privadas sem fins lucrativos com o Poder Público em serviços sociais livres à ação privada, fomentando a participação cidadã voluntária na esfera pública.

Não podem ser superestimadas nem subestimadas como respostas conseqüentes à crise do aparelho do Estado no âmbito da prestação dos serviços sociais. O Estado com elas não se despede da responsabilidade de assegurar e garantir os direitos sociais básicos. O Estado continuará regulador e promotor de serviços sociais, contando porém com mecanismos de parceria renovados, ampliando a sua capacidade de direta ou indiretamente assegurar a fruição dos direitos sociais fundamentais. ${ }^{11}$
}

\footnotetext{
${ }^{11}$ MODESTO, Paulo. Reforma administrativa e marco legal das organizações sociais no Brasil - as dúvidas dos juristas sobre o modelo das organizações sociais. Revista Diálogo Jurídico, Salvador, CAJ - Centro de Atualização Jurídica, v. I, no. 9, dezembro, 2001. Disponível em: http://www.direitopublico.com.br/pdf_9/DIALOGOJURIDICO-09-DEZEMBRO-2001-PAULO-MODESTO.pdf. Acesso em: 06 jul. 2018.
} 
A preconização da eficiência foi um dos fios condutores, inclusive, quando do julgamento final em 2015, da Ação Direta de Inconstitucionalidade (ADI) 1923, pelo Supremo Tribunal Federal, conforme explicitado no voto do Ministro Luiz Fux: "Na essência, preside a execução deste programa de ação institucional a lógica, que prevaleceu no jogo democrático, de que a atuação privada pode ser mais eficiente do que a pública em determinados domínios, dada a agilidade e a flexibilidade que marcam o regime de direito privado."12

Para Boaventura Sousa Santos, o terceiro setor é um conjunto de organizações que não são nem estatais nem mercantis, são animadas por objetivos sociais, públicos ou coletivos e não se constituem em entes estatais. ${ }^{13}$

Segundo Rubem César Fernandes, representante da vertente de que a "vida pública" não é feita apenas de atos do governo, mas também de atividade cidadã. Não apenas o governo, mas todos nós, organizações e iniciativas privadas possuem uma função pública. Neste sentido, o terceiro setor se destaca por representar expressões de solidariedade através de atividades autônomas e voluntárias, beneficiando diversos setores da população. Assim, coloca-se como uma alternativa inovadora e eficiente de resolução da "questão social". ${ }^{14}$

Nesta perspectiva, o terceiro setor é apresentado como uma alternativa inovadora, num processo de consolidação da democracia e do desenvolvimento social. É nesse sentido que as Organizações Sociais têm papel fundamental na dinâmica da Reforma do Estado, principalmente no setor dos serviços não-exclusivos do Estado. Assim, como uma das alternativas para a superação da crise do Estado foram criadas as Organizações Sociais, para agilizar e tornar eficiente os serviços públicos. O Estado assim há que redefinir sua atuação no desempenho de suas funções sociais e aperfeiçoar a vertente da administração gerencial.

\begin{abstract}
A estratégia da reforma do Estado se apóia na publicização dos serviços não exclusivos do Estado, ou seja, na sua absorção por um setor público não-estatal, onde, uma vez fomentados pelo Estado, assumirão a forma de organizações sociais. Essa forma de parceria entre sociedade e Estado, além de viabilizar a ação pública com mais agilidade e maior alcance, busca tornar mais fácil e direto o controle social, mediante a participação, nos conselhos de administração, dos diversos segmentos beneficiários envolvidos. As organizações nesse setor gozam de uma autonomia administrativa muito maior do que aquela possível dentro do aparelho do Estado. Em compensação, seus dirigentes são chamados a assumir uma responsabilidade maior, em conjunto com a sociedade, na gestão da instituição. ${ }^{15}$
\end{abstract}

${ }^{12}$ SUPREMO TRIBUNAL FEDERAL. Ação Direta de Inconstitucionalidade 1923. Voto - vista do Ministro Luiz Fux.

${ }^{13}$ SANTOS, Boaventura de Sousa. A Reinvenção Solidária e Participativa do Estado. IN. PEREIRA, L. C. Bresser (Org.). Sociedade e Estado em transformação. São Paulo: UNESP, 2001, p. 13.

${ }^{14}$ FERNANDES, Rubem César. Privado, porém público: o terceiro setor na América Latina. Rio de Janeiro: Relume - Dumará, 1994.

${ }^{15}$ BRASIL. Ministério da Administração Federal e Reforma do Estado. Organizações Sociais. Brasília: 1997, p.10. 
A publicização dos serviços não estatais funciona como estratégia para a recolocação do Estado brasileiro no cenário internacional de competitividade e permitindo que o mesmo se volte mais para a perspectiva gerencial que burocrática e busque cumprir com êxito as suas funções clássicas que não podem ser transferidas e estão intrinsecamente ligadas com as competências centrais do Estado.

\section{ALGUNS ASPECTOS JURÍDICOS - PRÁTICOS DA PUBLICIZAÇÃO NO BRASIL}

A Lei n. ${ }^{\circ}$ 9.637, de 15 de maio de 1998, que regula as Organizações Sociais, teve sua constitucionalidade questionada no STF, cujo processamento da Ação Direta de Inconstitucionalidade ficou pendente de julgamento até o ano de 2015. Nesse período teve voto do Relator Ministro Ayres Brito e, posteriormente, como Redator Ministro Luiz Fux.

Enquanto a ação abstrata estava sendo processada no STF, a administração pública federal continuou a fazer uso do expediente e os Estados foram criando suas legislações para dispor sobre a temática e implementar seus respectivos Programas nos Estados (Pará/1996; Bahia/1997).

Um ponto central no debate da constitucionalidade foi que a transferência dos serviços ofenderia o dever da administração de prestar os serviços públicos de saúde, educação, proteção ao meio ambiente, patrimônio histórico e acesso à ciência.

Nesse aspecto, é solar o entendimento que a administração pública pode viabilizar a sua atuação no domínio econômico e social, direta ou indiretamente, respectivamente, disponibilizando meios materiais aos beneficiários ou fazendo uso do seu instrumental jurídico para instigar entes privados a executarem atividades de interesses públicos.

Outro ponto questionado foi em relação ao Programa de Organizações Sociais ao supor que a administração pública ofenderia o princípio constitucional fundamental da não interferência estatal em associações. Entretanto, como preconizam às legislações federal e a do Estado da Bahia, as entidades sem fins lucrativos participaram do processo seletivo, consoante as suas vontades. Não sendo obrigatória à participação da entidade no certame.

Em 2015, o STF considerou constitucional a adoção do modelo de organizações sociais no Brasil, refutando a maior parte dos argumentos que ensejariam uma suposta inconstitucionalidade.

Rev. de Direito Administrativo E Gestão Pública | e-ISSN: 2526-0073 | Porto Alegre | v. 4 | n. 2 | p. 137 -151 | Jul/Dez. 2018 
De um modo geral, apesar do termo utilizado nas legislações referentes às organizações sociais ser "publicização" não parece restar dúvida de que se trata de uma "privatização" dos serviços públicos, desta vez para as entidades do terceiro setor.

Para José dos Santos Carvalho Filho, o que aconteceu foi o cumprimento de mais uma etapa do processo de desestatização, na qual o Estado tem se afastado da realização direta da atividade, ou, desejando da prestação direta de parte dos serviços públicos, mesmo não econômicos, delegando-os a pessoas de direito privado não integrantes da administração pública. ${ }^{16}$

É importante destacar que as Organizações Sociais embora inclusas no conjunto de entidades do terceiro setor, não foram contempladas na sistemática do Marco Regulatório das Organizações da Sociedade Civil, afastando a incidência dessa última norma.

De todo modo, o tratamento que a administração pública tem dispensado as entidades do terceiro setor, especialmente, as organizações sociais, estas se apresentam como uma realidade em que a administração pública não mais consegue prestar seus serviços sem a colaboração dessas entidades em determinadas áreas, especialmente, o Estado da Bahia, cujos dados evidenciam que aproximadamente $33,33 \%$ de seus leitos estão sendo gerenciados por organizações sociais.

Ainda, a administração pública não podendo terceirizar as suas atividades finalísticas recorrem às organizações sociais.

\section{CONSIDERAÇÕES FINAIS}

Como visto, não há um consenso em relação qual modelo de publicização o Brasil adotou. De todo modo, verifica-se que quando comparados os modelos, as práticas e perspectivas se assemelham.

De todo modo, como se percebe, tanto na França quanto na Inglaterra, buscou-se reformar o aparelho do Estado para atingir maior eficiência administrativa.

Isso mediante instrumentos consensuais que, por um lado, deram maior autonomia aos agentes públicos e, por outro, deles cobraram mais responsabilidade. O controle de resultados passou, então, a prevalecer sobre outros controles administrativos ou orçamentários.

\footnotetext{
${ }^{16}$ CARVALHO FILHO, José dos Santos. Manual de Direito Administrativo. 20. ed. Ver. Ampl. e atual. Rio de Janeiro: Lúmen Juris, 2008.
}

Rev. de Direito Administrativo E Gestão Pública | e-ISSN: 2526-0073 | Porto Alegre | v. 4 | n. 2 | p. 137 - 151 | Jul/Dez. 2018 
No Brasil, apesar das organizações sociais já estarem se aproximando de quase vinte anos de existência no ordenamento jurídico pátrio, a constitucionalidade durante quase todo período de sua existência esteve questionada, causando certa insegurança nos gestores públicos e nas entidades do terceiro setor.

A lógica que prevalece no âmbito das organizações sociais é a de que a atuação privada poderá ser mais eficiente do que a pública em decorrência da agilidade e a flexibilidade em relação aos procedimentos que poderão ser adotados.

De todo modo, as organizações sociais são mecanismo que a administração pública encontra para suprir a carência de pessoal e afastar dos limites estabelecidos na Lei de Responsabilidade Fiscal, além de permitir maior agilidade na efetivação do serviço.

As organizações sociais não podem receber recursos públicos dissociados das metas e indicadores em relação ao quantitativo e o qualitativo, assim como devem sofrer controle dos órgãos de controle no limite dos recursos financeiros concedidos e transferidos.

Essas entidades privadas colaboram para que a administração pública cumpra com uma de suas obrigações precípuas: prestar os serviços públicos aos cidadãos indistintamente.

Por fim, a governança pública deve ser de responsabilidade de todos, portanto, a participação das entidades do terceiro setor enseja mecanismos para a sociedade civil participar diretamente da gestão e da avaliação do uso dos recursos públicos.

\section{REFERÊNCIAS}

AVANÇO DO PROGRAMA ESTADUAL DE ORGANIZAÇÕES SOCIAIS AMPLIA SERVIÇOS PRESTADOS À POPULAÇÃO BAIANA. Disponível em: http://www.saeb.ba.gov.br/NoticiasView.aspx?noticia=7622-avanco-do-programa-estadualde-organizacoes-sociais-amplia-servicos-prestados-a-populacao-baiana. Acesso em: 08 jul. 2018.

BADIE, Bertrand. 2000. Um mundo sem soberania, os Estados entre o artifício e a responsabilidade. Lisboa: Instituto Piaget [Coleção Economia e Política] (Introdução, pp. 918; capítulo 4: As soberanias perdidas, pp. 123-174).

BAHIA. Secretaria da Administração. Organizações Sociais: guia de constituição. Salvador, 2004.

Rev. de Direito Administrativo E Gestão Pública | e-ISSN: 2526-0073 | Porto Alegre | v. 4 | n. 2 | p. 137 -151 | Jul/Dez. 2018 
BARBE, Roger. A estratégia francesa de renovação do serviço público. In: FUNDAÇÃo ESCOLA NACIONAL DE ADMINISTRAÇÃO PÚBLICA. Os contratos de gestão e a experiência francesa de renovação do setor público: Seminário Brasil/França, Brasília: SAF/ENAP, 1993.

BARRETO, Maria Inês. As organizações sociais na Reforma do Estado. In: O Público nãoestatal na Reforma do Estado. Rio de Janeiro: FGV 1999: p.107 -151.

BRASIL. Ministério da Administração Federal e Reforma do Estado. Organizações Sociais. Brasília: 1997.

Supremo Tribunal Federal. Ação Direta de Inconstitucionalidade 1923. Voto - vista do Ministro Luiz Fux.

BRESSER PEREIRA, Luis Carlos. A reforma do Estado dos Anos 90: lógica e mecanismos de controle. Lua Nova. n. 45, 98.

CARVAlHO FILHO, José dos Santos. Manual de Direito Administrativo. 20. ed. Rev.. Ampl. e atual. Rio de Janeiro: Lúmen Juris, 2008.

COELHO FILHO, Milton de Sousa. 15 ANOS DE ORGANIZAÇÕES SOCIAIS: o modelo baiano. $5^{\circ}$ Congresso de Gestão Pública. Brasília, 2012. Disponível em: http://www.organizacoessociais.com.br/wpcontent/uploads/2015/12/15_anos_de_organiza\%C 3\%A7\%C3\%B5es_sociais_o_modelo_baiano.pdf. Acesso em: 06 jul. 2018.

DI PIETRO, Maria Sylvia Zanella. Parcerias na administração pública: concessão, permissão, franquia, terceirização, parceria público-privada e outras formas. $6^{\mathrm{a}}$ ed. São Paulo: Atlas, 2008.

FERNANDES, Rubem César. Privado, porém público: o terceiro setor na América Latina. Rio de Janeiro: Relume - Dumará, 1994.

FUNDAÇÃO ESCOLA NACIONAL DE ADMINISTRAÇÃO PÚBLICA. O contrato de gestão no serviço público. Brasília: ENAP, 1993.

GADELHA, C.A. G. O complexo industrial da saúde e a necessidade de um enfoque dinâmico na economia da saúde. In: Ciência e Saúde Coletiva (8)2:

$521535-2003$. 
JUNIOR, Nivaldo Carneiro. O setor público não-estatal: as organizações sociais como possibilidades e limites na gestão pública da saúde. 2002. 242f. Tese (Doutorado em Medicina) Universidade de São Paulo, São Paulo, 2002.

MODESTO, Paulo. Reforma administrativa e marco legal das organizações sociais no Brasil as dúvidas dos juristas sobre o modelo das organizações sociais. Revista Diálogo Jurídico, Salvador, CAJ - Centro de Atualização Jurídica, v. I, n. 9, dezembro, 2001. Disponível em: http://www.direitopublico.com.br/pdf_9/DIALOGO-JURIDICO-09-DEZEMBRO-2001PAULO-MODESTO.pdf. Acesso em: 06 jul. 2018.

MONTAÑO, Carlos. Terceiro Setor e Questão Social: Crítica ao padrão emergente de intervenção social. São Paulo: Cortez, 2002.

OLIVEIRA, Gustavo Justino de. Contrato de gestão. São Paulo: Revista dos Tribunais, 2008. PALAZZO, José Luis, SESÍN, Domingo Juan e LEMBEYE, Víctor Armando Rolón. La Transformación del Estado. Buenos Aires, Ediciones Depalma, 1992.

SANTOS, Boaventura de Sousa. A Reinvenção Solidária e Participativa do Estado. IN. PEREIRA, L. C. Bresser (Org.). Sociedade e Estado em transformação. São Paulo: Unesp, 2001, p. 13.

SANTOS, Boaventura de Souza. Um discurso sobre as ciências. $7^{\text {a }}$ ed. São Paulo: Cortez, 2010 .

VIOLIN, Tarso Cabral. Terceiro setor e as parcerias com a Administração Pública: uma análise crítica. Belo Horizonte: Fórum, 2006. 